Article

\title{
Chemical and Enantioselective Analysis of the Leaf Essential Oil from Piper coruscans Kunth (Piperaceae), a Costal and Amazonian Native Species of Ecuador
}

\author{
Gianluca Gilardoni ${ }^{D}$, Yadira Matute and Jorge Ramírez *(D) \\ Departamento de Química y Ciencias Exactas, Universidad Técnica Particular de Loja, Calle M. Champagnat s/n, \\ Loja 1101608, Ecuador; gianluca.gilardoni@gmail.com (G.G.); yadiram6644@gmail.com (Y.M.) \\ * Correspondence: jyramirez@utpl.edu.ec
}

Received: 4 June 2020; Accepted: 18 June 2020; Published: 24 June 2020

check for updates

\begin{abstract}
In the present study, an essential oil was distilled from the leaves of Piper coruscans Kunth, a native Amazonian species belonging to the family Piperaceae and quite common in Ecuador. The chemical analysis was performed by GC-MS (qualitative) and GC-FID (quantitative), on polar and non-polar columns, detecting a total of 58 compounds of which 52 were identified. All the identified compounds were quantified. The essential oil was mainly constituted of sesquiterpenes (54.1-55.0\%) and oxygenated sesquiterpenoids (32.5-33.6\%), the major constituents being: (E)- $\beta$-caryophyllene (24.1-25.0\%), $\alpha$-humulene (11.6-12.0\%), caryophyllene oxide $(9.3-10.9 \%)$, linalool (4.5-5.2\%), humulene epoxide II (3.6-4.1\%), (E)-nerolidol (3.7-4.0\%), $\alpha$-copaene (3.7-3.9\%), $\alpha$-muurolol $(3.4-3.7 \%), \alpha$-selinene $(3.4-3.5 \%), \beta$-selinene $(3.1-3.3 \%)$, and one undetermined oxygenated sesquiterpenoid (3.1-3.3\%). The aqueous phase (hydrolate) of the distillation process was also submitted to chemical analysis, showing linalool as the main organic compound in solution, with a concentration of $12.3-15.7 \mathrm{mg} / 100 \mathrm{~mL}$. The essential oil was than analyzed for the enantiomeric distribution of its monoterpene constituents, affording the following enantiomeric excesses in two $\beta$-cyclodextrin-based enantioselective columns: (1S,5S)-(-)- $\alpha$-pinene $(60.0-69.6 \%)$, $(1 S, 5 S)-(-)-\beta$-pinene (5.2-7.2\%), (R)-(-)- $\alpha$-phellandrene (72.5-78.2\%), (R)-(+)-limonene $(28.6 \%)$ and (R)-(-)-linalool (1.8-3.1\%).
\end{abstract}

Keywords: Piper coruscans; Artanthe amazonica; Piper amazonicum; essential oil; GC-MS; GC-FID; enantioselective analysis; Ecuador

\section{Introduction}

Ecuador is a small country located across the Equatorial line, overlooking the Pacific Ocean in the northern portion of the South American continent. It is geographically and climatically divided in four main regions: The islands (Galapagos), the coast, the Andean region, and the Amazonian forest. Each one of these zones is characterized by a peculiar climate, what makes biodiversity an incredible strength for the country. That is why Ecuador has been recognized by the UN Environment Program World Conservation Monitoring Centre as one of the 17 megadiverse countries in the world, counting by definition with "at least 5000 of the world's plants as endemics" [1].

Every year, botanists discover and describe in Ecuador new botanical species, that are added to the approximately 16,000 already known. According to the most complete botanical publication on the Ecuadorian flora [2], 15,306 native species were known in 1999, of which 4173 were endemic. Most of the native plants described in this country have never been investigated so far for what concerns their metabolic composition [3]. This is the reason why the authors have been studying for many years the secondary metabolites of the Ecuadorian flora, in order to give a contribution to the knowledge in phytochemistry and phytopharmacolgy. 
Among the natural products the authors are interested in, we can cite essential oils (EOs) [4-11]. According to the European Pharmacopeia, an EO is an "odorous product, usually of complex composition, obtained from a botanically defined plant raw material by steam distillation, dry distillation, or a suitable mechanical process without heating. Essential oils are usually separated from the aqueous phase by a physical process that does not significantly affect their composition" [12]. In this context, the authors decided to describe the chemical and enantiomeric composition of the EO distilled from the leaves of Piper coruscans Kunth.

Piper coruscans is a species belonging to the family Piperaceae, described as a native plant of the coast and Amazonian regions of Ecuador and growing wild between 0-500 $\mathrm{m}$ above sea level [2]. Nevertheless, it has been described in many other countries, from French Guyana to Brazil, from Venezuela to Colombia, from Peru to Bolivia [13]. Piper coruscans is also known with many synonyms: Artanthe amazonica Miq., Artanthe coruscans (Kunth) Miq., Artanthe pseudochurumayu (Kunth) Miq., Piper amazonicum (Miq.) C. DC., Piper baryanum C. DC., Piper coactaepilum Trel., Piper coruscans var. membranaceum (C. DC.) Steyerm., Piper orenocanum C. DC., Piper pseudochurumayu (Kunth) C. DC., Piper pseudochurumayu var. membranaceum C. DC., Piper santiaganum Trel., Piper tingens Trel., Piper wurdackii Yunck., Schilleria coruscans (Kunth) Kunth, and Steffensia pseudochurumayu Kunth [13].

According to a recent comprehensive review on the phytochemistry of genus Piper, the leaves of P. coruscans are used in traditional medicine as a purgative. Furthermore, the decoction is considered effective to treat high fevers, whereas the warmed leaves are reduced to poultice to treat swollen abdomen in children [14].

Despite a lot of literature exists about the chemistry of genus Piper, only about $10 \%$ of all known Piper species have been submitted to a phytochemical study [14]. For what concerns P. coruscans, seven references have been found in literature. Six of them were related to the chemistry, synthesis, and biological activity of non-volatile extracts and metabolites (mainly coruscanones) [15-19], whereas only one cited the essential oil [20]. However, nowhere the chemical or the enantioselective analysis was reported. On the other hand, no literature was found about any synonyms of this species, whereby, to the best of the authors' knowledge, this study describes for the first time an EO distilled from Piper coruscans Kunth.

\section{Results}

\subsection{Chemical Analysis}

The essential oil was obtained with a distillation yield of $0.4 \pm 0.26 \%$ from fresh plant material. The chemical analyses were performed on two different columns, a non-polar one (DB-5ms) and a polar one (HP-INNOWax), detecting a total of 58 compounds. Most of the constituents (52) were identified by comparing the electron impact mass spectrum (EIMS) and the linear retention index (LRI) with literature, whereas 6 remained unidentified. According to their molecular weight, the unknown components are consistent with one sesquiterpene (204 amu) and five oxygenated sesquiterpenoids (220 and $222 \mathrm{amu}$ ). For what concerns the quantitative analysis, 46 identified constituents, corresponding to about $91 \%$ of the EO, could be quantified on at least one column, whereas 6 compounds (camphene, p-cymene, terpinen-4-ol, cyclosativene, $\beta$-cubebene, and aromadendrene) appeared as traces $(<0.1 \%)$ in both columns. In this case, due to the abundance of oxygenated terpenoids, the existence of an important residual organic fraction dissolved in the aqueous phase (hydrolate) was supposed. Hence, the distillation water phase was analyzed in the same conditions of the EO, after concentration by solid phase extraction (SPE). The results were expressed as milligrams of analytes per $100 \mathrm{~mL}$ of water. The main organic substance in solution was linalool, with an abundance of $12.3-15.7 \mathrm{mg} / 100 \mathrm{~mL}$. All the analytical results are reported in Table 1. 
Table 1. Chemical analysis of Piper coruscans essential oil.

\begin{tabular}{|c|c|c|c|c|c|c|c|c|c|c|c|c|c|}
\hline \multirow{3}{*}{ N. } & \multicolumn{5}{|c|}{ Constituents } & \multicolumn{4}{|c|}{ Essential Oil } & \multicolumn{4}{|c|}{ Hydrolate } \\
\hline & \multirow{2}{*}{ Identification } & \multicolumn{2}{|c|}{ DB-5ms } & \multicolumn{2}{|c|}{ HP-INNOWax } & \multicolumn{2}{|c|}{ DB-5ms } & \multicolumn{2}{|c|}{ HP-INNOWax } & \multicolumn{2}{|c|}{ DB-5ms } & \multicolumn{2}{|c|}{ HP-INNOWax } \\
\hline & & LRI $^{1}$ & LRI $^{2}$ & LRI $^{1}$ & LRI $^{3}$ & $\%^{4}$ & $\sigma^{5}$ & $\%^{4}$ & $\sigma^{5}$ & $\mathrm{mg} / 100 \mathrm{~mL}$ & $\sigma^{5}$ & $\mathrm{mg} / 100 \mathrm{~mL}$ & $\sigma^{5}$ \\
\hline 1 & $\alpha$-pinene & 925 & 932 & 1014 & $1028^{6}$ & 2.4 & 0.77 & 3.0 & 0.94 & - & - & - & - \\
\hline 2 & camphene & 936 & 946 & 1056 & $1075^{6}$ & trace & - & trace & - & - & - & - & - \\
\hline 3 & $\beta$-pinene & 968 & 974 & 1103 & $1118^{6}$ & 1.3 & 0.20 & 1.6 & 0.25 & - & - & - & - \\
\hline 4 & myrcene & 986 & 988 & 1163 & $1166^{7}$ & 0.1 & 0.04 & 0.2 & 0.03 & - & - & - & - \\
\hline 5 & $\alpha$-phellandrene & 1001 & 1002 & 1159 & $1167^{7}$ & trace & - & 0.2 & 0.03 & - & - & - & _. \\
\hline 6 & $\delta$-3-carene & 1003 & 1008 & 1142 & $1144^{7}$ & trace & 0.04 & 0.1 & 0.04 & - & - & - & - \\
\hline 7 & limonene & 1023 & 1024 & 1194 & $1197^{8}$ & 0.5 & 0.34 & 0.7 & 0.27 & - & - & - & - \\
\hline 8 & $p$-mentha-2,4(8)-diene & 1078 & 1085 & 1278 & - & 0.1 & 0.23 & trace & - & - & - & - & - \\
\hline 9 & p-cymene & 1019 & 1020 & 1267 & $1281^{6}$ & trace & - & trace & - & - & - & - & - \\
\hline 10 & 1,8-cineole & 1025 & 1026 & 1201 & $1220^{9}$ & 0.3 & 0.20 & 0.5 & 0.26 & 0.6 & 0.20 & 0.4 & 0.06 \\
\hline 11 & linalool & 1100 & 1095 & 1555 & $1556^{6}$ & 5.2 & 2.10 & 4.5 & 1.79 & 15.7 & 1.42 & 12.3 & 1.95 \\
\hline 12 & terpinen-4-ol & 1172 & 1174 & - & - & trace & - & trace & - & 0.3 & 0.02 & 0.3 & 0.05 \\
\hline 13 & $\alpha$-terpineol & 1188 & 1186 & - & - & 0.2 & 0.09 & trace & - & 1,0 & 0.07 & 0.8 & 0.13 \\
\hline 14 & $\alpha$-cubbebene & 1337 & 1348 & 1449 & $1461^{7}$ & 0.2 & 0.03 & 0.2 & 0.04 & - & - & - & - \\
\hline 15 & cyclosativene & 1352 & 1369 & 1465 & $1522^{10}$ & trace & - & trace & - & - & - & - & - \\
\hline 16 & $\alpha$-copaene & 1363 & 1374 & 1479 & $1502^{6}$ & 3.7 & 0.74 & 3.9 & 0.73 & - & - & - & - \\
\hline 17 & $\beta$-bourbonene & 1369 & 1387 & 1507 & $1517^{7}$ & 0.1 & 0.03 & 0.2 & 0.02 & - & - & - & - \\
\hline 18 & $\beta$-cubebene & 1376 & 1387 & 1530 & $1542^{11}$ & trace & - & trace & - & - & - & - & - \\
\hline 19 & $\beta$-elemene & 1379 & 1389 & - & - & 0.2 & 0.07 & trace & - & - & - & - & - \\
\hline 20 & $\alpha$-gurjunene & 1392 & 1400 & 1518 & $1530^{12}$ & 0.2 & 0.06 & 0.2 & 0.08 & - & - & - & - \\
\hline 21 & $(E)$ - $\beta$-caryophyllene & 1405 & 1417 & 1587 & $1589^{13}$ & 24.1 & 5.31 & 25.0 & 5.26 & - & - & - & - \\
\hline 22 & $\beta$-copaene & 1414 & 1430 & 1581 & $1579^{14}$ & 0.3 & 0.06 & 0.3 & 0.02 & - & - & - & - \\
\hline 23 & $\beta$-ylangene & 1421 & 1419 & 1562 & $1576^{14}$ & 0.1 & 0.03 & 0.1 & 0.04 & - & - & - & - \\
\hline 24 & aromadendrene & 1425 & 1439 & 1632 & $1637^{15}$ & trace & - & trace & - & - & - & - & - \\
\hline 25 & $\beta$-gurjunene & 1434 & 1431 & 1579 & $1590^{7}$ & trace & - & 0.4 & 0.09 & - & - & - & - \\
\hline 26 & 6,9-guaiadiene & 1440 & 1442 & 1658 & $1674^{6}$ & 0.1 & 0.03 & trace & - & - & - & - & - \\
\hline 27 & $\alpha$-humulene & 1454 & 1452 & 1668 & - & 11.6 & 1.80 & 12.0 & 1.70 & - & - & - & - \\
\hline 28 & cis-cadina-1(6),4-diene & 1462 & 1465 & 1772 & $1788^{14}$ & 0.4 & 0.08 & trace & - & - & - & - & . \\
\hline 29 & cis-muurola-4(14),5-diene & 1465 & 1461 & - & - & 0.4 & 0.20 & trace & - & - & - & - & - \\
\hline 30 & $\beta$-selinene & 1472 & 1489 & 1706 & $1705^{8}$ & 3.3 & 0.47 & 3.1 & 0.38 & - & - & - & - \\
\hline 31 & $\alpha$-selinene & 1480 & 1498 & 1712 & $1725^{14}$ & 3.5 & 0.44 & 3.4 & 0.49 & - & - & - & - \\
\hline 32 & bicyclogermacrene & - & - & 1722 & $1734^{14}$ & trace & - & 0.2 & 0.03 & - & - & - & - \\
\hline 33 & $\gamma$-muurolene & 1483 & 1478 & 1697 & $1689^{14}$ & 0.6 & 0.30 & 0.5 & 0.24 & - & - & - & _. \\
\hline 34 & $\alpha$-amorphene & 1486 & 1483 & 1679 & $1676^{16}$ & 0.7 & 0.23 & 0.4 & 0.03 & - & - & - & - \\
\hline 35 & valencene & 1498 & 1496 & 1699 & $1728^{14}$ & 0.5 & 0.05 & 0.4 & 0.04 & - & - & - & . \\
\hline 36 & $\alpha$-muurolene & 1502 & 1511 & 1717 & $1734^{6}$ & 0.2 & 0.16 & 0.4 & 0.24 & - & - & - & - \\
\hline 37 & $\delta$-cadinene & 1506 & 1522 & 1750 & $1764^{6}$ & 2.8 & 0.19 & 2.8 & 0.33 & - & - & - & - \\
\hline 38 & trans-cadina-1,4-diene & 1518 & 1533 & - & - & 0.1 & 0.08 & - & - & - & - & - & - \\
\hline 39 & cis/trans-calamenene & - & - & 1824 & $1834^{6}$ & trace & - & 0.3 & 0.06 & - & - & - & - \\
\hline 40 & trans-cadina-1(6),4-diene & - & - & 1882 & - & trace & - & 0.7 & 0.25 & - & - & - & - \\
\hline 41 & $\alpha$-cadinene & 1522 & 1537 & 1783 & $1769^{6}$ & 0.1 & 0.03 & trace & - & - & - & - & - \\
\hline 42 & $\alpha$-calacorene & 1525 & 1544 & 1907 & $1914^{16}$ & 0.2 & 0.03 & 0.2 & 0.07 & - & - & - & - \\
\hline 43 & $\beta$-calacorene & 1546 & 1564 & 1948 & $1940^{6}$ & 0.3 & 0.17 & trace & - & - & - & - & - \\
\hline 44 & (E)-nerolidol & 1558 & 1561 & 2045 & $2051^{6}$ & 4.0 & 1.10 & 3.7 & 0.97 & - & - & - & - \\
\hline 45 & caryophyllene oxide & 1564 & 1582 & 1964 & $1989^{6}$ & 10.9 & 3.38 & 9.3 & 2.52 & 0.6 & 0.09 & 0.5 & 0.11 \\
\hline 46 & humulene epoxide II & 1591 & 1608 & 2023 & $2047^{14}$ & 4.1 & 1.25 & 3.6 & 1.10 & 0.4 & 0.10 & 0.2 & 0.06 \\
\hline 47 & ledol & 1583 & 1602 & 2016 & $2035^{12}$ & 0.2 & 0.16 & 0.2 & 0.10 & - & - & - & - \\
\hline 48 & spathulenol & - & - & 2118 & $2126^{6}$ & trace & - & 1.3 & 0.52 & 0.4 & 0.07 & 0.3 & 0.05 \\
\hline 49 & caryophylla-4(12),8(13)-dien-5 $\alpha$-ol & 1618 & 1639 & 2293 & $2301^{17}$ & 2.0 & 1.40 & 1.6 & 0.67 & trace & - & 0.2 & 0.05 \\
\hline 50 & $\alpha$-muurolol (= torreyol) & 1633 & 1644 & 2195 & $2142^{12}$ & 3.7 & 1.30 & 3.4 & 1.32 & 0.6 & 0.09 & 0.5 & 0.13 \\
\hline 51 & 14-hyroxy-(Z)-caryophyllene & 1657 & 1666 & 2378 & - & 2.0 & 0.89 & 1.9 & 0.65 & - & - & - & - \\
\hline \multirow[t]{7}{*}{52} & amorpha-4,9-dien-2-ol & 1671 & 1700 & 2358 & - & 0.6 & 0.40 & 0.4 & 0.16 & - & - & - & - \\
\hline & Monoterpene hydrocarbons & & & & & 4.4 & & 5.8 & & - & & - & \\
\hline & Oxygenated monoterpenes & & & & & 5.7 & & 5.0 & & 17.6 & & 13.8 & \\
\hline & Sesquiterpene hydrocarbons & & & & & 53.7 & & 54.7 & & - & & - & \\
\hline & Oxygenated sesquiterpenes & & & & & 27.5 & & 25.4 & & 2.0 & & 1.7 & \\
\hline & Others & & & & & - & & - & & - & & - & \\
\hline & Total & & & & & 91.3 & & 90.9 & & 19.6 & & 12.1 & \\
\hline
\end{tabular}

${ }^{1}$ Calculated linear retention indices (LRI); ${ }^{2}$ reference linear retention indices according to [21]; ${ }^{3}$ reference linear retention indices according to other literature; ${ }^{4}$ percentage quantitative analysis; ${ }^{5}$ standard deviation; trace $<0.1 \%$; $\mathrm{mw}=$ molecular weight; ${ }^{6}[22] ;{ }^{7}[23] ;{ }^{8}[24] ;{ }^{9}[25] ;{ }^{10}[26] ;{ }^{11}[27] ;{ }^{12}[28] ;{ }^{13}[29] ;{ }^{14}[30] ;{ }^{15}[31] ;{ }^{16}[32] ;{ }^{17}[33]$.

\subsection{Enantioselective Analysis}

The enantioselective analysis was performed on two enantioselective columns: a 2,3-diethyl-6-tert-butyldimethylsilyl- $\beta$-cyclodextrin and a 2,3-diacetyl-6-tert-butyldimethylsilyl- $\beta$ cyclodextrin based capillary columns. A total of five enantiomeric pairs were identified, all belonging to the class of monoterpenes and monoterpenoids. None of the detected chiral compounds was enantiomerically pure. The complete enantioelective analysis is represented in Table 2. 
Table 2. Enantioselective analysis of some chiral constituents of P. coruscans EO on 2,3-diethyl-6tert-butyldimethylsilyl- $\beta$-cyclodextrin and 2,3-diacetyl-6-tert-butyldimethylsilyl- $\beta$-cyclodextrin.

\begin{tabular}{|c|c|c|c|c|c|c|}
\hline \multirow{2}{*}{ Enantiomers } & \multicolumn{3}{|c|}{ 2,3-Diethyl-6-tert-Butyldimethylsilyl- $\beta$-Cyclodextrin } & \multicolumn{3}{|c|}{ 2,3-Diacetyl-6-tert-Butyldimethylsilyl- $\beta$-Cyclodextrin } \\
\hline & LRI $^{1}$ & Enantiomeric Distribution (\%) & e.e. $(\%)$ & LRI $^{1}$ & Enantiomeric Distribution (\%) & e.e. $(\%)$ \\
\hline$(1 R, 5 R)-(+)-\alpha$-pinene & 927 & 15.2 & \multirow[b]{2}{*}{69.6} & 975 & 20.0 & \multirow{2}{*}{60.0} \\
\hline$(1 S, 5 S)-(-)-\alpha$-pinene & 928 & 84.8 & & 970 & 80.0 & \\
\hline$(1 R, 5 R)-(+)-\beta$-pinene & 953 & 47.4 & \multirow[b]{2}{*}{5.2} & 1041 & 46.4 & \multirow[b]{2}{*}{7.2} \\
\hline$(1 S, 5 S)-(-)-\beta-$-pinene & 961 & 52.6 & & 1039 & 53.6 & \\
\hline$(R)-(-)-\alpha$-phellandrene & 1017 & 86.3 & \multirow{2}{*}{72.5} & 1092 & 89.1 & \multirow[b]{2}{*}{78.2} \\
\hline (S)-(+)- $\alpha$-phellandrene & 1117 & 13.7 & & 1158 & 10.9 & \\
\hline$(S)-(-)$-limonene & 1052 & 35.7 & \multirow{2}{*}{28.6} & 1121 & unseparable & \multirow[t]{2}{*}{ - } \\
\hline$(R)-(+)$-limonene & 1067 & 64.3 & & 1121 & & \\
\hline$(R)-(-)$-linalool & 1187 & 51.5 & \multirow[b]{2}{*}{3.1} & 1384 & 50.9 & \multirow[b]{2}{*}{1.8} \\
\hline (S)-(+)-linalool & 1198 & 48.5 & & 1386 & 49.1 & \\
\hline
\end{tabular}

${ }^{1}$ Linear retention index (LRI); e.e. $=$ enantiomeric excess.

\section{Discussion}

According to literature [14], some authors classify the EOs distilled from the species of genus Piper into six categories, depending on their chemical composition: EOs dominated by monoterpenes (mainly limonene, sabinene, $\beta$-pinene, $\alpha$-pinene, and piperitone), EOs dominated by sesquiterpenes (typically $\beta$-caryophyllene, germacrene $D, \beta$-elemene, epi-cubebol, $\beta$-guaiene, and $\beta$-bisabolene), EOs equally dominated by both families of terpenoids, EOs dominated by phenylpropanoids (for example safrole, dillapole, eugenol, chavibetol, and (Z)-asarone), EOs dominated by benzenoid compounds and EOs dominated by non-terpenoid compounds (usually derivatives from the acetate pathway). Observing the chemical analysis performed in the present study, we can conclude that the EO distilled from the leaves of $P$. coruscans clearly belongs to the second group. In fact, despite $\alpha$-pinene, $\beta$-pinene and linalool were present in a significant amount, about $80 \%$ of the chemical composition corresponded to sesquiterpenes and sesquiterpenoids. In particular, (E)- $\beta$-caryophyllene (24.1-25.0\%), $\alpha$-humulene (11.6-12.0\%), and caryophyllene oxide (9.3-10.9\%) were clearly dominant. In this case, the plant material was freshly distilled after collection and the EO immediately injected, what makes the authors think that no artefact was significantly produced. However, caryophyllene oxide is sometime considered as a result of aging in a $(E)$ - $\beta$-caryophyllene containing EO. If this were the case, the real amount of $(E)$ - $\beta$-caryophyllene would overpass $30 \%$. The very high content of $(E)$ - $\beta$-caryophyllene makes $P$. coruscans EO relatively quite similar to the one obtained from fruits of P. nigrum (black pepper), where the abundance of this sesquiterpene ranges normally between $15-50 \%$ but it can rise until $70 \%$ in some Malaysian cultivars [14]. The high amount of $(E)-\beta$-caryophyllene also opens the way to the study of interesting biological properties for this $\mathrm{EO}$, according to great number of bioactivities described in literature for this sesquiterpene [34].

For what concerns the aqueous phase that spontaneously separates from an EO after distillation, commonly called hydrolate, it is well known that sometimes it has an important commercial value, such is the case for example of rose water or mint water. For the EO of P. coruscans, the high content of oxygenated terpenoids suggested that an important residue could remain dissolved in water, which effectively presented a clear sweet odor. The chemical analysis of the hydrolate revealed that linalool is actually the very most abundant organic solute, reaching the concentration of about $15 \mathrm{mg} / 100 \mathrm{~mL}$ (150 ppm), what explains the perceived aroma.

The chemical analysis of this essential oil was complemented with the enantioselective one, where the enantiomeric distribution and the enantiomeric excess (e.e.) of some monoterpenes and monoterpenoids were determined and confirmed on two different enantioselective columns. None of the detected chiral metabolites was present in its enantiomerically pure form, however $\beta$-pinene and linalool were almost racemic, with just a small e.e. in favor of $(1 S, 5 S)-(-)-\beta$-pinene and $(R)-(-)$-linalool. 


\section{Materials and Methods}

\subsection{Plant Material}

The leaves of $P$. coruscans were collected on April 2018 in the province of Zamora-Chinchipe, near town Zamora, at coordinates $04^{\circ} 05^{\prime} 00^{\prime \prime} \mathrm{S}$ and $078^{\circ} 57^{\prime} 00^{\prime \prime} \mathrm{W}$. The plant was collected under permission $\mathrm{N}^{\circ}$ 001-IC-FLO-DBAP-VS-DRLZCH-MA, emitted by the Ministry of Environment of Ecuador. The species was identified by botanist Dr. Vladimir Morocho of the Universidad Técnica Particular de Loja (UTPL) and a voucher specimen was deposited at the herbarium of UTPL with code PPN-pi-010.

\subsection{Distillation of the Essential Oil and Sample Preparation}

In order to obtain the pure essential oil, $3 \mathrm{~kg}$ of fresh plant material were preparatively hydrodistilled for $4 \mathrm{~h}$, inside a stainless-steel Clevenger-type apparatus. After recovery of the organic layer, the EO was dried over anhydrous sodium sulphate. For all the GC injections, $10 \mathrm{mg}$ of EO were weighted and diluted with $1 \mathrm{~mL}$ of cyclohexane, previously prepared with an internal standard (n-nonane) at the concentration of $0.7 \mathrm{mg} / \mathrm{mL}$. Additionally, four portions of $10 \mathrm{~mL}$ of the water layer were collected and eluted on previously conditioned solid phase extraction (SPE) columns. After complete removal of water from the solid phase, the analytes were recovered by elution with $2 \mathrm{~mL}$ of acetone prepared, as previously described for cyclohexane, dissolving $n$-nonane as internal standard $(0.7 \mathrm{mg} / \mathrm{mL})$. The acetone solutions were directly injected into GC. The SPE columns were standard products, packed with $1 \mathrm{~g}$ of C-18 reversed phase and purchased from Sigma-Aldrich.

Additionally, four analytical repetitions were performed hydrodistilling the essential oil inside a micro-scale Marcusson-type apparatus [35]. In this case, $10 \mathrm{~g}$ of fresh plant material were distilled for $90 \mathrm{~min}$ and the volatile fraction was collected in $400 \mu \mathrm{L}$ of an extractive organic layer (cyclohexane containing $0.7 \mathrm{mg} / \mathrm{mL}$ of $n$-nonane as internal standard). The cyclohexane layers were recovered and directly injected into GC.

In this study, all the samples were transferred to amber vials and kept at $-15{ }^{\circ} \mathrm{C}$ until use. After verifying the similarity of the GC profile between preparative and analytical repetitions, all the five samples were used to calculate the mean distillation yield and afforded the mean quantitative results, both provided with standard deviation.

All the solvents used in this study (analytical grade, purity $>99 \%$ ) were purchased from Sigma-Aldrich.

\subsection{Qualitative Chemical Analysis}

The qualitative chemical analyses were performed with a gas chromatography-mass spectrometry (GC-MS) system, constituted by an Agilent Technologies gas chromatograph 6890N coupled to a simple quadrupole Mass Spectrometry Detector (MSD) model 5973 (Santa Clara, CA, USA). The MSD was operated in SCAN mode, with an electronic ionization source of $70 \mathrm{eV}$. The ion detection was limited to the range of $35-350 \mathrm{~m} / \mathrm{z}$. The transfer line was set at the temperature of $280^{\circ} \mathrm{C}$, the MS ion source at $200^{\circ} \mathrm{C}$. The gas chromatograph was configurated with a DB-5ms non-polar (5\%-phenyl-methylpolysiloxane, $30 \mathrm{~m}, 0.25 \mathrm{~mm}$ internal diameter, and $0.25 \mu \mathrm{m}$ film thickness; J \& W Scientific, Folsom, CA, USA) and a HP-INNOWax polar (polyethylene glycol, $30 \mathrm{~m}, 0.25 \mathrm{~mm}$ internal diameter and $0.25 \mu \mathrm{m}$ film thickness; Agilent Technologies, Santa Clara, CA, USA) capillary columns.

The GC-MS analyses on DB-5ms were performed as follow: the carrier gas was helium, set at constant flow, with a rate of $1 \mathrm{~mL} / \mathrm{min}$. All the chromatographic runs were performed injecting $1 \mu \mathrm{L}$. The injector was set in split mode (40:1), with an injection temperature of $250{ }^{\circ} \mathrm{C}$. The elution was conducted from $50{ }^{\circ} \mathrm{C}(1 \mathrm{~min})$ to $250{ }^{\circ} \mathrm{C}(10 \mathrm{~min})$ at a gradient rate of $3{ }^{\circ} \mathrm{C} / \mathrm{min}$.

The same conditions and thermal program were used for the analyses on HP-INNOWax, except for the final temperature, that just reached $230^{\circ} \mathrm{C}$ due to the lower thermal stability of the stationary phase. 
In order to identify the components of the EO, the linear retention index (LRI) of each constituent was calculated according to Van Den Dool and Kratz [36] and compared to literature, together with the corresponding mass spectrum (see Table 1). LRIs were calculated through the homologous series of linear alkanes, using a mixture from $n$-nonane to $n$-pentacosane ( $n$-nonane purity was $99 \%$ from $\mathrm{BDH}$, Dubai, UAE. $\mathrm{C}_{10}-\mathrm{C}_{25}$ purity was $99 \%$ from Sigma-Aldrich, St. Louis, MO, USA).

\subsection{Quantitative Chemical Analysis}

The quantitative analyses were run in the same GC instrument as the qualitative ones, configured with a Flame Ionization Detector (FID) and equipped with an Agilent Technologies 7683 series autoinjector (Little Falls, DE, USA).

The analytical conditions were the same described for the qualitative analyses, but with a different thermal program. In fact, with DB-5ms column, the initial temperature of $50{ }^{\circ} \mathrm{C}$ was kept for $1 \mathrm{~min}$, followed by a thermal gradient of $3{ }^{\circ} \mathrm{C} / \mathrm{min}$ until $180^{\circ} \mathrm{C}$, then a second thermal gradient of $15^{\circ} \mathrm{C} / \mathrm{min}$ until $250^{\circ} \mathrm{C}$. The final temperature was maintained for $15 \mathrm{~min}$. For what concerns the analysis on HP-INNOWax, the same GC method as DB-5ms was applied, except for the final temperature that only reached $230{ }^{\circ} \mathrm{C}$. The FID was alimented with a mixture of hydrogen and air, at the flow of $30 \mathrm{~mL} / \mathrm{min}$ and $300 \mathrm{~mL} / \mathrm{min}$ respectively. The detector was set at the temperature of $250{ }^{\circ} \mathrm{C}$. In order to quantify the analytes, a relative response factor (RRF) was calculated for each component, according to the respective combustion enthalpy $[37,38]$. In this respect, A. Chaintreau and colleagues demonstrated that the RRF of an organic compound, analyzed by FID, only depends, with good approximation, on its molecular formula and number of aromatic rings. According to this principle, they described a mathematical formula [38], that permits to estimate the RRF toward a quantification standard (usually methyl octanoate). In our case, a modified method was actually applied, since isopropyl caproate was used instead of methyl octanoate and two calibration curves (one for each column) have been used instead of a single point internal standard. The isopropyl caproate was prepared by synthesis in one of the authors' laboratory (G.G.) and its purity was calculated by GC as $97 \%$. For calibration curves construction, six calibration standard dilutions were prepared, dissolving $0.6,1.8,4.3,8.3,16.8$, and $34.3 \mathrm{mg}$ of isopropyl caproate in $10 \mathrm{~mL}$ of cyclohexane respectively. As usual, an amount of $7.0 \mathrm{mg}$ of $n$-nonane was used as internal standard inside each dilution. Both calibration curves generated a correlation coefficient of 0.995 .

\subsection{Enantioselective GC Analysis}

The enantioselective analyses were carried out in the same previously described GC-MS system, measuring the enantiomeric relative percentage and the enantiomeric excesses (e.e.). The instrument was equipped with a 2,3-diethyl-6-tert-butyldimethylsilyl- $\beta$-cyclodextrin and a 2,3-diacetyl-6-tert-butyldimethylsilyl- $\beta$-cyclodextrin enantioselective columns, both $25 \mathrm{~m} \times 0.25 \mathrm{~mm} \times$ film thickness $0.25 \mu \mathrm{m}$ from Mega, Legnano, Italy.

The following thermal program was applied: $50{ }^{\circ} \mathrm{C}$ maintained for $5 \mathrm{~min}$, then a gradient temperature of $2{ }^{\circ} \mathrm{C} / \mathrm{min}$ until $220^{\circ} \mathrm{C}$, that were kept for $5 \mathrm{~min}$. The enantiomer order of elution was determined through the injection, in the same instrumental conditions, of mixtures of enantiomerically pure standards.

\section{Conclusions}

The leaves of Piper coruscans Kunth contain a volatile fraction of prevalently sesquiterpene composition. The hydrodistillation of the leaves produces an essential oil, whose known major compounds are $(E)-\beta$-caryophyllene (24.1-25.0\%), $\alpha$-humulene (11.6-12.0\%), caryophyllene oxide (9.3-10.9\%), linalool (4.5-5.2\%), humulene epoxide II (3.6-4.1\%), (E)-nerolidol (3.7-4.0\%), $\alpha$-copaene (3.7-3.9\%), $\alpha$-muurolol (3.4-3.7\%), $\alpha$-selinene (3.4-3.5\%), and $\beta$-selinene (3.1-3.3\%). The sesquiterpene fraction of this EO counts for more than $80 \%$ of the chemical composition. For what concerns the monoterpene fraction, at least five of its chiral components subsist as mixtures of enantiomeric pairs. 
Author Contributions: Conceptualization, G.G.; data curation, G.G. and J.R.; investigation, Y.M.; supervision, J.R.; writing-original draft, G.G.; writing—review and editing, G.G., J.R. All authors have read and agreed to the published version of the manuscript.

Funding: This research received no external funding.

Acknowledgments: We are very grateful to Carlo Bicchi (University of Turin, Italy) for his advice. We are also grateful to the Universidad Técnica Particular de Loja (UTPL) for supporting open access publication.

Conflicts of Interest: The authors declare no conflict of interest.

\section{References}

1. Megadiverse Countries, UNEP-WCMC. Available online: https://www.biodiversitya-z.org/content/ megadiverse-countries (accessed on 31 May 2020).

2. Jorgensen, P.; Leon-Yanez, S. Catalogue of the Vascular Plants of Ecuador; Missouri Botanical Garden Press: St. Louis, MO, USA, 1999.

3. Malagón, O.; Ramírez, J.; Andrade, J.; Morocho, V.; Armijos, C.; Gilardoni, G. Phytochemistry and ethnopharmacology of the Ecuadorian flora. A review. Nat. Product Commun. 2016, 11, 297-314.

4. Ramírez, J.; Gilardoni, G.; Jácome, M.; Montesinos, J.; Rodolfi, M.; Guglielminetti, M.; Cagliero, C.; Bicchi, C.; Vidari, G. Chemical composition, enantiomeric analysis, AEDA sensorial evaluation and antifungal activity of the essential oil from the Ecuadorian plant Lepechinia mutica BENTH (Lamiaceae). Chem. Biodivers. 2017, 14, e1700292. [CrossRef]

5. Calva, J.; Bec, N.; Gilardoni, G.; Larroque, C.; Cartuche, L.; Bicchi, C.; Montesinos, J. Acorenone B: $\mathrm{AChE}$ and BChE inhibitor as a major compound of the essential oil distilled from the Ecuadorian species Niphogeton dissecta (Benth.) J.F.Macbr. Pharmaceuticals 2017, 10, 84. [CrossRef]

6. Herrera, C.; Morocho, V.; Vidari, G.; Bicchi, C.; Gilardoni, G. Phytochemical investigation of male and female Hedyosmum scabrum (RUIZ \& PAV.) SOLM leaves from Ecuador. Chem. Biodivers. 2018, 15, e1700423. [CrossRef]

7. Ramirez, J.; Gilardoni, G.; Ramón, E.; Tosi, S.; Picco, A.; Bicchi, C.; Vidari, G. Phytochemical study of the Ecuadorian species Lepechinia mutica (Benth.) Epling and high antifungal activity of carnosol against Pyricularia oryzae. Pharmaceuticals 2018, 11,33. [CrossRef] [PubMed]

8. Gilardoni, G.; Ramirez, J.; Montalvan, M.; Quinche, W.; León, J.; Benítez, L.; Morocho, V.; Cumbicus, N.; Bicchi, C. Phytochemistry of three Ecuadorian Lamiaceae: Lepechinia heteromorpha (Briq.) Epling, Lepechinia radula (Benth.) Epling and Lepechinia paniculata (Kunth) Epling. Plants 2018, 8, 1. [CrossRef] [PubMed]

9. Espinosa, S.; Bec, N.; Larroque, C.; Ramirez, J.; Sgorbini, B.; Bicchi, C.; Gilardoni, G. Chemical, enantioselective, and sensory analysis of a cholinesterase inhibitor essential oil from Coreopsis triloba S.F. Blake (Asteraceae). Plants 2019, 8, 448. [CrossRef] [PubMed]

10. Montalván, M.; Peñafiel, M.; Ramirez, J.; Cumbicus, N.; Bec, N.; Larroque, C.; Bicchi, C.; Gilardoni, G. Chemical composition, enantiomeric distribution, and sensory evaluation of the essential oils distilled from the Ecuadorian species Myrcianthes myrsinoides (Kunth) Grifo and Myrcia mollis (Kunth) DC. (Myrtacee). Plants 2019, 8, 511. [CrossRef]

11. García, J.; Gilardoni, G.; Cumbicus, N.; Morocho, V. Chemical analysis of the essential oil from Siparuna echinata (Kunth) A. DC. (Siparunaceae) of Ecuador and isolation of the rare Terpenoid Sipaucin A. Plants 2020, 9, 187. [CrossRef]

12. Council of Europe European Pharmacopoeia-8th Edition; Council of Europe: Strasbourg, France, 2013 ; p. 743.

13. Tropicos.org. Missouri Botanical Garden. Available online: http://legacy.tropicos.org/Name/25000528?tab= distribution (accessed on 31 May 2020).

14. Salehi, B.; Zakaria, Z.A.; Gyawali, R.; Ibrahim, S.A.; Rajkovic, J.; Shinwari, Z.K.; Khan, T.; Sharifi-Rad, J.; Ozleyen, A.; Turkdonmez, E.; et al. Piper species: A comprehensive review on their phytochemistry, biological activities and applications. Molecules 2019, 24, 1364. [CrossRef]

15. Vásquez-Ocmín, P.; Gallard, J.F.; Van Baelen, A.C.; Leblanc, K.; Cojean, S.; Mouray, E.; Grellier, P.; Amasifuén, C.; Bernadat, G.; Evanno, L.; et al. Antiplasmodial biodereplication based on highly efficient methods. ChemRxiv 2020, 1. [CrossRef] 
16. Khan, H.; Sabbah, D.A.; Zafar, M.; Mubarak, M.S. Molecular modeling studies of coruscanone (A) core nucleus as potential antifungal agents. Life Sci. 2018, 209, 332. [CrossRef] [PubMed]

17. Shestak, O.P.; Novikov, V.L. Synthesis of coruscanones A and B, metabolites of Piper coruscans, and related compounds. Rus. Chem. Bull. 2010, 59, 81. [CrossRef]

18. Shestak, O.P.; Novikov, V.L.; Martyyas, E.A.; Anisimov, M.M. Synthesis and antimicrobial and antifungal activities of cyclopentene $\beta, \beta^{\prime}$-triketones and their methyl enol ethers. Pharmaceut. Chem. J. 2009, 43, 498. [CrossRef]

19. Li, X.C.; Ferreira, D.; Jacob, M.R.; Zhang, Q.; Khan, S.I.; El Sohly, H.N.; Nagle, D.G.; Smillie, T.J.; Khan, I.A.; Walker, L.A.; et al. Antifungal cyclopentenediones from Piper coruscans. J. Am. Chem. Soc. 2004, 126, 6872. [CrossRef] [PubMed]

20. Tangarife-Castano, V.; Correa-Royero, J.B.; Roa-Linares, V.C.; Pino-Benitez, N.; Betancur-Galvis, L.A.; Duran, D.C.; Stashenko, E.E.; Mesa-Arango, A.C. Anti-dermatophyte, anti-Fusarium and cytotoxic activity of essential oils and plant extracts of Piper genus. J. Essent. Oil Res. 2014, 26, 221. [CrossRef]

21. Adams, R.P. Identification of Essential Oil Components by Gas Chromatography/Mass Spectrometry, 4th ed.; Allured Publishing Corporation: Carol Stream, IL, USA, 2007; ISBN 10-1932633219.

22. Kundakovic, T.; Fokialakis, N.; Chinou, I. Essential oil composition of Achillea lingulata and A. umbellata. Flavour Fragr. J. 2008, 3820, 67.

23. Flamini, G.; Tebano, M.; Cioni, P.L.; Bagci, Y.; Dural, H.; Ertugrul, K.; Savran, A. A multivariate statistical approach to Centaurea classification using essential oil composition data of some species from Turkey. Plant Syst. Evol. 2006, 261, 217. [CrossRef]

24. Flamini, G.; Cioni, P.L.; Morelli, I.; Bader, A.; Katbeh-Bader, A. Composition of the essential oil of leaves, galls, and ripe and unripe fruits of Jordanian Pistacia palaestina Boiss. J. Agricult. Food Chem. 2007, 52, 572. [CrossRef]

25. Christensen, L.P.; Jakobsen, H.B.; Paulsen, E.; Hodal, L.; Andersen, K.E. Airborne Compositae dermatitis: Monoterpenes and no parthenolide are released from flowering Tanacetum parthenium (Feverfew) plants. Arch. Dermatol. Res. 1999, 291, 425. [CrossRef]

26. Bader, A.; Caponi, C.; Cioni, P.L.; Flamini, G.; Morelli, I. Composition of the essential oil of Ballota undulata, B. nigra ssp. foetida and B. saxatilis. Flavour Fragr. J. 2003, 18, 502. [CrossRef]

27. Bertoli, A.; Pistelli, L.; Morelli, I.; Fraternale, D.; Giamperi, L.; Ricci, D. Volatile constituents of different parts (roots, stems and leaves) of Smyrnium olusatrum L. Flavour Fragr. J. 2004, 19, 522. [CrossRef]

28. Aromdee, C.; Anorach, R.; Sriubolmas, N. Essential oil of the flower of Azadirachta indica (Meliaceae). Acta Hortic. 2005, 679, 11. [CrossRef]

29. Bicchi, C.; Rubiolo, P.; Saranz Camargo, E.E.; Vilegas, W.; de Souza Gracioso, J.; Monteiro Souza Brito, A.R. Components of Turnera diffusa Willd. var. afrodisiaca (Ward) Urb. essential oil. Flavour Fragr. J. 2003, 18, 59. [CrossRef]

30. Babushok, V.I.; Linstrom, P.J.; Zenkevich, I.G. Retention indices for frequently reported compounds of plant essential oils. J. Phys. Chem. Ref. Data 2011, 40, 47. [CrossRef]

31. Saroglou, V.; Marin, P.D.; Rancic, A.; Veljic, M.; Skaltsa, H. Composition and antimicrobial activity of the essential oil of six Hypericum species from Serbia. Biochem. Syst. Ecol. 2007, 35, 146. [CrossRef]

32. Martinez, J.; Rosa, P.T.V.; Menut, C.; Leydet, A.; Brat, P.; Pallet, D.; Meireles, M.A.A. Valorization of brazilian vetiver (Vetiveria zizanioides (L.) Nash ex Small) oil. J. Agricult. Food Chem. 2004, 52, 6578. [CrossRef]

33. Osorio, C.; Alarcon, M.; Moreno, C.; Bonilla, A.; Barrios, J.; Garzon, C.; Duque, C. Characterization of odor-active volatiles in champa (Campomanesia lineatifolia R. \& P.). J. Agricult. Food Chem. 2006, 54, 509.

34. Francomano, F.; Caruso, A.; Barbarossa, A.; Fazio, A.; La Torre, C.; Ceramella, J.; Mallamaci, R.; Saturnino, C.; Iacopetta, D.; Sinicropi, M.S. $\beta$-Caryophyllene: A Sesquiterpene with countless biological properties. Appl. Sci. 2019, 9, 5420. [CrossRef]

35. Bicchi, C.; D'Amato, A.; Frattini, C. Improved method for the analysis of small amounts of essential oils by microdistillation followed by capillary gas chromatography. J. Chromatogr. 1983, 279, 409. [CrossRef]

36. Van Den Dool, H.; Kratz, P.D. A generalization of the retention index system including linear temperature programmed gas-liquid partition chromatography. J. Chromatogr. A 1963, 11, 463. [CrossRef] 
37. De Saint Laumer, J.Y.; Cicchetti, E.; Merle, P.; Egger, J.; Chaintreau, A. Quantification in gas chromatography: Prediction of flame ionization detector response factors from combustion enthalpies and molecular structures. Anal. Chem. 2010, 82, 6457. [CrossRef] [PubMed]

38. Tissot, E.; Rochat, S.; Debonneville, C.; Chaintreau, A. Rapid GC-FID quantification technique without authentic samples using predicted response factors. Flavour Fragr. J. 2012, 27, 290. [CrossRef]

(C) 2020 by the authors. Licensee MDPI, Basel, Switzerland. This article is an open access article distributed under the terms and conditions of the Creative Commons Attribution (CC BY) license (http://creativecommons.org/licenses/by/4.0/). 